CLINICAL ETHICS

\title{
Should children's autonomy be respected by telling them of their imminent death?
}

\author{
T Vince, A Petros
}

$J$ Med Ethics 2006;32:21-23. doi: 10.1136/jme.2005.011700

Respect for an individual's autonomy determines that doctors should inform patients if their illness is terminal. This becomes complicated when the terminal diagnosis is recent and death is imminent. The authors examine the admission to paediatric intensive care of an adolescent with terminal respiratory failure. While fully ventilated, the patient was kept sedated and comfortable but when breathing spontaneously he was capable of non-verbal communication and understanding. Once resedated and reintubated, intense debate ensued over whether to wake the patient to tell him he was going to die. The authors discuss the ethical arguments that surrounded their decision.

\footnotetext{
A
} 14 year old boy was admitted to the paediatric intensive care unit (PICU) with acute on chronic respiratory failure and was mechanically ventilated. He was known to have obliterative bronchiolitis secondary to an episode of Stevens-Johnson syndrome. He also had a past history of IgG2 subclass deficiency and phenylketonuria but was developmentally normal. He had severely impaired lung function with both forced expiratory volume (FEVl) and forced vital capacity (FVC) at around $20 \%$ of that predicted for his age and was receiving home oxygen. He was being considered for lung transplantation.

Throughout the admission he was difficult to ventilate but five days after admission he was extubated. He was, however, unable to maintain adequate spontaneous ventilation and rapidly deteriorated, requiring reintubation under sedation and reventilation. It soon became apparent that, rather than just an acute deterioration of respiratory function following a chest infection, this was the presentation of terminal respiratory failure. A multidisciplinary discussion involving the respiratory, transplant, and intensive care teams and the boy's parents took place to review the management options. The lung disease was felt to be irreversible and of such severity and progression as to be rapidly terminal. It was agreed by all that lung transplantation was not a viable option as transplantation in children ill enough to need mechanical ventilation had previously been uniformly unsuccessful. It was also unanimously agreed that to continue aggressive intensive therapy, including tracheotomy and short term chronic ventilation, was futile in the face of deteriorating lung function and inadequate gas exchange. There was uniform consensus that withdrawal of therapy was the only option.

Having achieved unanimous agreement on this point, intense discussion took place regarding how best to proceed. One view was that as the boy had been able to communicate and show understanding immediately prior to this admission, sedation should be stopped, he should be woken up fully, and given the opportunity to be aware of his terminal condition. Awakening him would also allow him to express and exercise his choices around his death, in particular, the chance to say goodbye to his family, and make his last wishes known. An opposing view felt, however, that it was wrong to wake him up just to tell him he was going to die. There were also concerns about how competent the decision making of an adolescent with respiratory failure and hypercapnia could be. The deciding factor was the boy's parents, who felt strongly that it would be too distressing for their son to wake him and discuss his inevitable death. A multidisciplinary ethical meeting was held to discuss the dilemma. It was ultimately agreed that the parent's wishes should be respected. The boy was not woken up, all infusions were maintained and he was extubated. He died comfortably in his sleep in the company of his family.

\section{DISCUSSION}

This case provoked considerable debate amongst those caring for the child. Our patient was felt to have no chance of recovery. He had severe lung disease and it was agreed that life sustaining treatment would only "delay death without significant alleviation of suffering", thereby fulfilling category four of the guidelines from the Royal College of Paediatrics and Child Health on withholding or withdrawing life saving treatment in children. ${ }^{1}$ All those looking after the child were agreed on this point. There were, however, two differing viewpoints on how to proceed and manage the child's death. One felt the young boy should be fully awoken from his sedation and informed of his imminent death because he had the right to know and that not to do so would deprive him of his autonomy and his right to be involved in discussions surrounding his imminent death. The contrasting view was that he should be kept comfortable and adequately sedated and have treatment withdrawn; to wake up the child and inform him of his death would be cruel and unnecessary. This was recognised as a paternalistic approach but felt to be in the child's best interests and was the viewpoint supported by the parents.

It was argued that if the child was deemed competent and capable of understanding his terminal situation, the medical team had an ethical duty to inform him of their discussions and decisions and to involve him in the process of his own death. By not doing so were the team violating his personhood, autonomy, and human rights? An individual has "personhood" if he is able to value his own existence and has hopes and desires for his future life. ${ }^{2}$ An individual's right to life emanates from that personhood rather than his innate biological form. ${ }^{3}$ With personhood comes the benefit of autonomy, in that we place a high moral value on the ability and freedom to make choices consistent with our hopes and desires. ${ }^{2}$ In fact, many would argue that respect for autonomy is the highest moral principle because it embodies the essence of being a person. ${ }^{2}{ }^{4}$ In acknowledging personhood, we are duty bound to respect autonomy and the right to self

Abbreviations: PICU, paediatric intensive care unit 
determination. Thus, recognition of the child's personhood was integral to respect for his life. Clearly, before his admission the boy was functioning normally at school and, for all purposes, was a person. By ensuring the boy remained comfortable and allowing him to die peacefully, without the stress of being awoken only to discuss his imminent death, the team was exercising an extreme degree of paternalism, which denied his autonomy and his right to self determination.

Before this admission, the boy had been living a normal but restricted life and on PICU, while intubated and mechanically ventilated but with sedation lifted, he had demonstrated good non-verbal communications. As such, there was no reason to believe that he would not have been able to understand the gravity of his condition. Nonetheless, it was suggested that he was too young to cope with the knowledge of his death. Yet it is well recognised that children with chronic illnesses, as young as 10 years old, can be aware they are dying and can benefit from participating in decisions surrounding death such as funeral arrangements. ${ }^{5}$ In retrospect, this case highlights the need for early and ongoing discussions about death with children with chronic illnesses. In this case, the child was aware of the chronic nature of his condition and the probable need for lung transplantation in the future. Discussions about death had not been previously broached with him, however, as they had not seemed pertinent to his primary physicians. Furthermore, on this admission, his acute deterioration was more rapid and severe than expected and it was unclear how he would have coped with this type of discussion in his current condition. Nevertheless, some members of the team felt he should be allowed the option. Indeed, if the outcome of withdrawal of therapy is the death of a person who is able to understand then should not consent be sought irrespective of age? Allmark would argue that this paternalistic approach to withdrawal of treatment, for fear of causing distress, denies a child his personhood and is unacceptable. ${ }^{6}$

During the boy's admission, and while ventilated, the advice of the specialist teams was that if he was unable to breathe spontaneously and was dependent upon mechanical support, his chances of successful lung transplantation were extremely poor. The PICU team relayed this opinion to the family, but until the child required reintubation this was merely a probability rather than fact. Thus the future management plans were dependent upon how the child responded. Moreover, the speed of his respiratory deterioration further precluded discussions of death and dying during the admission to PICU including prior to the trial of extubation. It is standard practice to anaesthetise children for intubation and then sedate them while ventilated, not least to avoid the physical consequences of fear and discomfort, and the child agreed to this. By the time the child was reintubated, the multidisciplinary meeting with his parents had not occurred. When it did take place, the medical teams, and in particular the transplant team, confirmed the child was not suitable for lung transplantation while dependent on mechanical ventilation. Consequently, the child remained entirely unaware of the ultimate significance of resedation and reintubation.

All parties agreed that the child was clearly not capable of consent whilst sedated. Subsequent discussions focused on whether the sedation should be lifted while maintaining the child on mechanical ventilation to allow him to be involved in decisions around his death with minimal impact on his respiratory status. Perhaps the real ethical dilemma centres, however, on the purpose of awakening the child. Was it to obtain his consent for withdrawal of treatment, or was it to inform him of his imminent death so that he could "put his affairs in order"? Some members of the team were concerned that the boy's respiratory failure and subsequent hypercapnia might have compromised his level of consciousness and competence, thereby affecting his ability to consent. An individual's competence arises from his experiences and values, not his chronological age. ${ }^{78}$ Moreover, competence has differing ethical and legal definitions. A person is deemed competent if he is able to assimilate information, apply it personally, and thereafter make an informed decision. In medicolegal terms, a competent person may consent to or refuse a treatment as long as he or she is fully informed, including being cognisant of the consequences. It is an ethical and statutory requirement to seek consent prior to treatment of a competent person and to respect his choice to refuse treatment even if it not in his best interests. ${ }^{25}$ The situation is different for children. The Gillick ruling in 1985 stated that a child deemed competent could consent to treatment ${ }^{9}$ but later judgments ruled that although competent children could consent to treatment, they could not refuse it, and could be overruled by parents or doctors. ${ }^{10}$ In ethical terms, maintaining a distinction between accepting and declining treatment have different moral values attached to them when in fact they are exactly equal but opposite. More importantly, the legal standpoint questions the value of consent of children in paediatric critical care in general. If the child remains sedated, he is incapable of consent and is the passive recipient of the discussions and actions of others. In contrast, awakening the child might enable him to consent, but is this truly possible? Consent is the voluntary, uncoerced agreement to a proposal and is made by a competent, autonomous person in the full knowledge of the consequences. ${ }^{11}$ In this case, the doctors would continue to act in the patient's best interests by laying down the facts of his condition before him. They may even recommend a course of action, including withdrawal of intensive care support. By adopting a paternalistic attitude and using persuasive arguments, the medical staff assume an authority that directly impacts on the child's ability to concur freely and without coercion. As a result, the child is not truly autonomous and what we obtain from him is not consent but acquiescence ${ }^{2}$ : thus the issue of this competent child's autonomy has been, as it were, overlooked. If this argument is continued, awakening the child, in effect to obtain his acquiescence, may actually be unethical because his right to autonomy remains denied and the process may cause him distress and harm.

The alternative reason to awaken him, to allow him to "put his affairs in order," bears consideration. As the outcome is inevitable, it may be postulated that the child had no real choices except in controlling some elements of the manner of his death. The opportunity to say goodbye may be vital for the child and may prove helpful for the family at the time of their son's death and afterwards. Perhaps, for these reasons alone, awakening the child may be beneficial.

Ethical dilemmas concerning end of life decisions are an almost daily occurrence on the PICU. In recent years, more children die on the PICU as a result of withdrawal or limitation of life sustaining treatment than of unsuccessful attempts at resuscitation. ${ }^{12}$ Limitation of intensive care support is almost invariably agreed between staff and families. ${ }^{13}$ Sklansky, however, described withholding and withdrawing life sustaining treatment as passive euthanasia since death occurs due to the absence of a treatment that would otherwise have prolonged an unbearable existence. ${ }^{14}$ Medical and legal authorities accept this because it is considered to be in the patient's best interests. ${ }^{1015}$ In our case, there was a significant degree of medical paternalism and parental judgment exercised in concurring over withdrawal of therapy, which might have led Sklansky to describe it as paternalistic euthanasia. Concerns about competence because of residual sedation and respiratory failure, and the 
potential distress the patient might suffer meant that obtaining consent was abandoned. Under these circumstances, a surrogate party must act in the person's best interests. In most situations on PICU, this will be the child's family as they have shared beliefs and values and are best placed to know the patient. ${ }^{14}$ It is unclear, however, how well a third party can act as a proxy. Meyer et al report that many parents feel they have little or no control in the process of their child's death and, in retrospect, up to $25 \%$ would change things. ${ }^{16}$ In addition, parents are sometimes unable to act in the child's best interests because of emotional stress or conflicts of interests. ${ }^{6}{ }^{17}$ Furthermore, several studies indicate that families do not accurately predict the resuscitation directives of their sick relative and may, therefore, instruct doctors differently from how the patient would have wished. ${ }^{18}$ Healthcare professionals can be helpful, as they tend to be more experienced and objective about the child's medical condition. Like parents, healthcare professionals consider the patient's quality of life, potential for recovery, and pain relief in their decision making. ${ }^{19}$ Doctors are not, however, ethically obliged to provide any treatment they believe is not beneficial to the patient and, indeed, are ethically obliged to avoid such interventions ${ }^{20}$. Hence, a paternalistic approach, albeit motivated by beneficence and non-maleficence, runs the risk of imposing on the family the physician's own values and interpretations of the child's best interests. $^{14} 192122$ Moreover, studies comparing staff and patient estimates of quality of life following spinal cord injury clearly demonstrate that healthcare professionals are more pessimistic than the patient's perception of, or indeed, the actual subsequent quality of life. ${ }^{23}$ When disagreement occurs or differences cannot be resolved, it is often very helpful to seek the advice of the local clinical ethics committee $^{1724}$ as was done in this case. There is no doubt that the decision would have been harder to uphold if the parents had held differing opinions about what ought to be done, or had not been firm in their view of how their child should be cared for in the terminal stages of his illness.

In the end, the team decided to withdraw intensive care support without informing the child. It was felt that the manner in which the child died would be much more significant for the family than for the various sections of the medical team. The parents were adamant that they did not want to risk any chance that their son might be distressed if awoken. By acquiescing with the parents' wishes, the medical team allowed them some control in their son's death. The actions of the healthcare team and the parents may be described as paternalistic, but based on the ethical principle of non-maleficence, the healthcare team acted in what they perceived to be the best interests of the child. In doing so, they prioritised their own and the parents' non-maleficent decisions over the patient's right to autonomy. This may well have been the right thing to do. It may also be argued that the nature and acute circumstances of his illness never truly allowed the child to determine his future. The question remains, however, whether an individual's best interests can truly be respected if he is denied the opportunity to exercise his autonomy.

\section{Authors' affiliations}

T Vince, A Petros, Paediatric Intensive Care Unit, Great Ormond Street Hospital, London, WCIN 3JH, UK

Correspondence to: T Vince, Paediatric Intensive Care Unit, Great Ormond Street Hospital, London, WCIN 3JH, UK; VinceT1@gosh.nhs. uk

Received 12 January 2005

In revised form 19 April 2005

Accepted for publication 20 April 2005

\section{REFERENCES}

1 Royal College of Paediatrics and Child Health. Withholding or withdrawing life saving treatment in children: a framework for practice. London: $\mathrm{RCPCH}$, 1997.

2 Harris J. Consent and end of life decisions. J Med Ethics 2003;29:10-15.

3 Tooley M. Decision to terminate life and the concept of person. In: Beauchamp T, Perlin S, eds. Ethical issues relating to life \& death. New York: Oxford University Press, 1979:64-5.

4 Gillon R. Ethics needs principles-four can encompass the rest-and respect for autonomy should be "first among equals". J Med Ethics 2003;29:307-12.

5 Himelstein BP, Hilden JM, Morstad Boldt A, et al. Pediatric palliative care. N Eng J Med 2004;350:1752-62.

6 Allmark P. Death with dignity. J Med Ethics 2002;28:255-7.

7 Sensky T. Withdrawal of life sustaining treatment. BMJ, 2002;325;175-96.

8 Street K, Ashcroft R, Henderson J, et al. The decision making process regarding the withdrawal or withholding of potential life saving treatments in a children's hospital. J Med Ethics 2000;26:346-52.

9 Gillick v West Norfolk and Wisbech Area Health Authority [1985] 3 All ER 402 (HL).

10 Re J [1991] Fam 33.

11 Habiba MA. Examining consent within the patient doctor relationship. J Med Ethics 2000;26:183-7.

12 Balfour-Lynn IM, Tasker RC. Futility and death in paediatric medical intensive care. J Med Ethics 1996;22:279-81.

13 Van der Heide A, van der Maas PJ, van der Wal G, et al. The role of parents in end of life decisions in neonatology: physicians' views and practices. Pediatrics 1998;101:413-18.

14 Sklansky M. Neonatal euthanasia: moral considerations and criminal liability. $J$ Med Ethics 2001;27:5-11.

15 Hatherill M, Tibby SM, Sykes K, et al. Dilemmas exist in withdrawing ventilation from dying children. BMJ 1998;317:80

16 Meyer EC, Burns JP, Griffith $\sqcup$, et al. Parental perspective on end of life care in the pediatric intensive care unit. Crit Care Med 2002;30:226-31.

17 Gladsjo JA, Breding J, Sine D, et al. Termination of life support after severe child abuse: the role of a guardian ad litem. Pediatrics 2004;113:e141-5.

18 Cherniack EP. Increasing use of DNR orders in the elderly worldwide: whose choice is it? J Med Ethics 2002;28:303-7.

19 Burns JP, Mitchell C, Outwater K, et al. End of life care in the paediatric intensive care after the forgoing of life sustaining treatment. Crit Care Med 2000;28:3060-6

20 General Medical Council. Withholding and withdrawing life prolonging treatment: Good practice in decision making. London: GMC, 2002.

21 Lee SK, Penner PL, Cox M. Comparison of the attitudes of health care professionals and parents towards active treatment of very low birth weight infants. Pediatrics 1991;88:110-14.

22 Gillon R. Primum non nocere in paediatrics. In: Burgio G, Lantos, eds. Primum non nocere today-a symposium on paediatric ethics. Amsterdam: Elsevier, 1994, Excerpta medica international congress series, 1073.

23 Patterson DR, Miller-Perrin C, McCormick TR, et al. When life support is questioned early in the care of patients with cervical level quadriplegia. N Eng J Med 1993;328:506-9.

24 Larcher V. Role of clinical ethics committees. Arch Dis Child 1999;81:104-6. 